\title{
Atividade Antimicrobiana de Óleos Essenciais Contra Salmonella Schwarzengrund multirresistente
}

Jaqueline Fronza Walker (I), Palloma de Souza Santos (I), Eleidiana Andréia Seixas de Oliveira (I), Marcelle Mota de Queiroz (I), Cleber Alberto Schimdt (I), Alaíse Gil Guimarães (I)

(I) UFBA - Universidade Federal da Bahia (Barão de Jeremoabo, 147; Ondiana, Salvador- BA)

\section{Resumo}

Os óleos essenciais são produtos extraídos de plantas e exibem importantes propriedades antimicrobianas, antitoxigênicas e antiparasitárias. A garantia da segurança de se ter alimentos com características nutricionais e organolépticas conservadas,e o fato de que os consumidores estão cada vez mais dando preferência a alimentos saudáveis e livres de conservantes sintéticos é o que tem motivado o estudo de óleos essenciais para aplicação em alimentos. O objetivo do trabalho foi avaliar a atividade antimicrobiana de quatro óleos essenciais, bem como determinar qual apresentamelhor desempenho frente a cepa de Salmonella Schwarzengrund multirresistente. Os óleos essenciais de alecrim (Rosmarinus officinalis), manjericão (Ocimum basilicum), manjerona verdadeira (Origanum majorana) e manjerona silvestre (Thymus mastichina) foram obtidos comercialmente da empresa Laszlo. Inicialmente avaliou-se a atividade antimicrobiana dos óleos essenciais pelo método de difusão em agar com discos, utilizando-se dimetilsulfóxido PA (DMSO) como controle negativo.. Em seguida, foi avaliada a Concentração Inibitória Mínima (CIM) de cada óleo, utilizandose a mesma técnica de difusão, porém com cavidades no ágar. Os ensaios, em duplicata, foram realizados em três dias independentes. Dentre os quatro óleos avaliados, o que apresentou melhor atividade antimicrobiana foi a manjerona silvestre (Thymus mastichina), com halo de inibição de $10,5 \mathrm{~mm}$. A CIM é considerada a menor concentração em que ocorre

\footnotetext{
Referência:

Jaqueline Fronza Walker, Palloma de Souza Santos, Eleidiana Andréia Seixas de Oliveira, Marcelle Mota de Queiroz, Cleber Alberto Schimdt, Alaíse Gil Guimarães. Atividade Antimicrobiana de Óleos Essenciais Contra Salmonella Schwarzengrund Multirresistente. In: Anais do 12을 Congresso Latinoamericano de Microbiologia e Higiene de Alimentos - MICROAL 2014 [= Blucher Food Science Proceedings, num.1, vol.1]. São Paulo: Editora Blucher, 2014.

DOI $10.5151 /$ foodsci-microal-300
} 
inibição de crescimento bacteriano, com diâmetro de halo igual ou superior a 10mm. Pela análise da CIM, a menor concentração em que houve inibição foi de $50 \mu \mathrm{L} / \mathrm{mL}$ para os óleos testados. O óleo essencial de manjerona silvestre mostrou maior atividade antimicrobiana que os demais, podendo ser uma alternativa para utilização em alimentos. Porém, são necessários testes adicionais aplicando-se o óleo nos alimentos em que se deseja utilizar.

Palavras-Chave: antimicrobiano, óleo essencial, Salmonella Agência de Fomento: FAPESB 